\title{
Hidroelektrik Santral Rezervuar Verilerinin Enerji Üretimi Amaçlı Değerlendirilmesi
}

\author{
Faruk ORAL ${ }^{1 *}$, Rasim BEHÇET ${ }^{2}$, Kadir AYKUT $^{1}$ \\ ${ }^{1}$ Bitlis Eren Üniversitesi, Mühendislik Mimarlık Fakültesi, Makina Mühendisliği Bölümü, Bitlis \\ ${ }^{2}$ İnönü Üniversitesi, Mühendislik Fakültesi, Makina Mühendisliği Bölümü, Malatya
}

\begin{abstract}
Özet
Türkiye, zengin enerji kaynakları potansiyeline sahip olmasına rağmen, enerji ihtiyacının büyük bir kısmını ithal etmektedir. Bu potansiyellerden yenilenebilir enerji kaynakları en önde gelen ve mutlaka değerlendirilmesi gereken temiz enerji kaynağıdır. Yenilenebilir temiz enerji kaynaklarından biri olan hidrolik enerjinin, ülkemizde mevcut potansiyelinin tamamının enerji üretimi açısından değerlendirilmesi önem arz etmektedir. Bu çalışmada; hidroelektrik santral rezervuar verileri enerji üretimi amaçlı değerlendirilmiştir. $\mathrm{Bu}$ amaçla verilen örnek hidroelektrik santralin göl işletme eğrisi oluşturulmuştur. Santral gölüne gelen ve enerji üretimi esnasında geçen su hacmi hesaplanarak, santral gölünde depolanan su hacmi belirlenmiştir. Göl işletme eğrisi yardımıyla göl kotu değeri belirlenerek, hidroelektrik santralin net düşüsü bulunmuştur. Bu veriler kullanılarak Mart 2014 tarihi için örnek hidroelektrik santralin enerji üretim miktarı yaklaşık olarak 94.928,927 $M W h$ hesaplanmıştır.
\end{abstract}

Anahtar kelimeler: Hidrolik Enerji, Hidroelektrik Santral, Rezervuar Verileri, Enerji Üretimi.

\section{The Assessment of Hydroelectric Power Plant Reservoir Data with the Purpose of Energy Production}

\begin{abstract}
Although Turkey has a rich energy resource potential, it imports a large part of energy needs. Renewable energy sources have a most important potential, and these sources are clean energy and must be evaluated. Hydraulic energy is one of the renewable clean energy sources and it is very crucial to evaluate all of Turkey's hydraulic energy potential in terms of producing energy. In this study; Hydroelectric power plant reservoir data were evaluated for energy production purposes. With this aim, the example of hydropower plant' lake operation curve is established. The volume of water stored in the plant's lake was determined with calculating water amount on both coming to the plant's lake and during energy production. With the help of the operation curve, lake elevation value was determined and a net drop in the hydroelectric power plant was found. Using this data, the amount of energy production of the example hydroelectric power plant for March 2014 was calculated as approximately 94.928,927 MWh.
\end{abstract}

Keywords: Hydraulic Energy, Hydroelectric Power Plant, Reservoir Data, Energy Production.

\section{Giriş}

Dünya nüfusundaki artışlar, sosyal refah ve hayat standardındaki gelişme ve beklentiler, sanayi ve teknolojideki hızlı gelişmeler, enerji tüketimini ve bunun sonucunda enerji talebini artırmaktadır. Mevcut enerji kaynaklarından olan fosil yakıtların üretiminde oluşan çevresel ve ekonomik zararlar, ülkeleri yeni enerji üretim kaynaklarına yöneltmiştir. Bunlardan en önemlisi yenilenebilir enerji kaynaklarıdır. Yenilenebilir enerji; kendisini sürekli olarak yenileyen, tükenmeyen, temiz enerji kaynağıdır. Bu yenilebilir enerji kaynaklarının bazıları hidrolik enerjisi, güneş enerjisi, rüzgâr enerjisi, jeotermal enerji ve biyokütle enerjisidir.

Hidrolik enerji yenilenebilir enerji kaynakları içerisinde enerji üretimi bakımından yaygın kullanıma

*Sorumlu yazar: foral@beu.edu.tr

Gelis Tarihi: 24/04/2017 Kabul Tarihi: 16/10/2017 
sahip enerji çeşididir. Hidrolik enerji yenilebilir olduğu için, çevresel önemi büyüktür. Ayrıca hidroelektrik enerjide herhangi bir hammadde tüketimi olmadığından dolayı fosil yakıtlı termik santrallere göre işletme masrafları oldukça düşüktür. Ek olarak, hidrolik santrallerde enerji üretimi, atmosfere büyük miktarda zararlı atıklar bırakan santrallere göre daha temizdir [1]. Hidroelektrik santraller, diğer enerji üretim sistemleri ile kıyaslandığında en az işletme maliyetine, en uzun işletme ömrüne ve en yüksek verime sahiptirler [2]. Depolamalı hidroelektrik santraller, taşkın ve baskınları engelleme, sulama işlerini kolaylaştırma, balıkçılığı geliştirme, ağaçlandırmaya destek olma, turizme katkı sağlama, ulaşım imkânlarını geliştirme vb. birçok avantaja sahiptir [3]. Elektrik enerjisi; kullanım kolaylığ 1 , tüm dünyada kullanım yaygınlığ 1 , istenildiğinde diğer enerji türlerine dönüştürülebilmesi, günlük hayatta yaygın olarak kullanılması gibi nedenlerden dolayı günümüzde vazgeçilmez bir ihtiyaç haline gelmiştir. Ekonomik gelişmenin ve bir toplumun sosyal refahının en önemli belirtilerinden birisi, tükettiği elektrik enerjisi miktarıdır. Dünyada elektrik, çeşitli kaynaklardan temin edilmektedir. Hidroelektrik enerji bu kaynaklardan bir tanesidir ve dünya yaygın kullanıma sahiptir.

Dünyanın değişik coğrafyalarında hidroelektrik santralleri için, uygun alanlar mevcuttur. Küçük hidroelektrik santraller, bilhassa diğer enerji santrallerinin yapılamadığı kırsal bölgelerde alternatif olarak kullanılmaktadır. Dünyada toplam hidroelektrik enerji üretiminin içerisinde küçük hidroelektrik santrallerinin payı, \%5-10 arasında değişmektedir [2-4].

Dünyanın brüt teorik hidroelektrik potansiyeli yaklaşık $40150 \mathrm{TWh} / \mathrm{yll}$ iken teknik olarak uygulanabilir potansiyeli $14060 \mathrm{TWh} / y l l$ ve günümüzde ekonomik olarak uygulanabilir hidroelektrik enerji potansiyeli $8905 \mathrm{TWh} / y \mathrm{l} l$ 'dır. 2006 yllında dünyada toplam hidroelektrik enerji üretimi 3121 $T W h$ 'dır. Bu değer dünyanın ekonomik olarak uygulanabilir hidroelektrik potansiyelinin yaklaşık $\% 35^{\prime}$ ine, teknik olarak uygulanabilir hidroelektrik potansiyelinin ise \%22'sine karş1lık gelmektedir [3, 5]. Dünyada en büyük hidroelektrik gücüne sahip Çin'in, $118 G W^{\prime}$ 'lk kurulu gücü ve yıllık $436 T W h$ üretimi vardır. Bu değerler tüm dünyadaki hidroelektrik enerji üretiminin \%14'ü, yerli elektrik üretimi olarak da\%15.2'lik bir değere sahiptir. Norveç'in hidroelektrik enerji üretiminin toplam yenilebilir enerji üretimi içerisindeki payı, \%98.5 değerindedir. Türkiye de ise yıllık $45.93 \mathrm{TWh}$ hidroelektrik enerjisi üretimi gerçekleşmiştir [3,6].

Türkiye'nin mevcut topoğrafik yapısı ve hidrolojik koşulları, hidroelektrik enerji üretimini avantajlı kılmaktadır. Türkiye'nin teorik hidroelektrik potansiyeli yıllık 433-442 TWh'tır. Türkiye'nin teknik hidroelektrik potansiyeli yaklaşık olarak yıllık $250 \mathrm{TWh}$ 'dır [7]. Ekonomik hidroelektrik potansiyeli ise yıllık $141 T W h$ 'dır [8]. Küçük kapasiteli hidroelektrik santrallerinin uygulanmaya alınması durumunda, bu kapasite yıllık 180-200 TWh'a çıkabilecektir [7]. Türkiye, bu verilere göre $\% 1$ ile Dünya'da 8. sırada, Avrupa'da ise \% 14 ile üçüncü sırada yer almaktadır [9-10]. Türkiye'de 2014 yılında elektrik enerjisi üretiminin $40.396 G W h^{\prime}{ }^{\prime} 1 \mathrm{k}$ kısmı hidrolik enerjiden gerçekleştirilmiştir. Türkiye'de kaynaklar bazında 2014 yılı için elektrik enerjisi üretiminin \%16,1'lik kısmı hidrolik enerjiden gerçekleşmiştir [11].

Son yıllarda tüm dünyada olduğu gibi Türkiye'de de artan enerji ihtiyacının karşılanmasında güvenilir, çevreci ve ekonomik enerji kaynakları önem kazanmaya başlamıştır. Bu bakımdan ülkemizde mevcut hidrolik enerji potansiyelimizin enerji üretimi amaçlı değerlendirilmesi önem arz etmektedir. Bir hidroelektrik santralde üretilecek enerji miktarını belirleyen en önemli büyüklükler debi ve düşü dür. Depolamalı hidroelektrik santrallerinde baraj gerisinde oluşturulan rezervuarda biriken suyun meydana getirdiği yapay göl ile birlikte düşü ve debiye olumlu katkı sağlandığ i için, üretilecek enerji artırılmış olur. $\mathrm{Bu}$ çalışmada; bir hidroelektrik santralin rezervuar verilerinin enerji üretim miktarının belirlenmesinde kullanılması amaçlanmıştır. Örnek bir hidroelektrik santral için bu veriler kullanılarak enerji üretimi miktarı yaklaşık hesaplanmıştır.

\section{Hidroelektrik Santraller}

Hidroelektrik santraller (HES), suyun potansiyel ve kinetik enerjisinden faydalanarak elektrik enerjisi elde edilen tesislerdir. Bu enerji, hidrolik santrallerde hidrolik türbinler yardımı ile mekanik enerjiye, türbinlerin tahrik ettiği jeneratörler ile elektrik enerjisine dönüştürülmektedir. Suyun düşü ve debisi türbinden elde edilecek güce, büyük oranda etki etmektedir. Düşü, üst su yüzeyi ile alt su yüzeyi arasındaki farktır. Düşü ve debi, türbinden elde edilecek güce, büyük oranda etki etmektedir $[10,12]$. 
Hidroelektrik santral en yaygın olarak; düşülerine, kurulu güce, depolama durumuna, baraj gövdesinin tipine ve santral binasının konumuna göre sinıflandırılabilir.

Kurulu güce göre sınıflandırmada, dünya genelinde kabul görmüş bir sınıflandırma bulunmamaktadır. Pek çok ülke büyük ve küçük hidroelektrik santralleri, farklı kurulu güce göre tanımlamaktadır. Genel olarak kurulu gücü; $100 \mathrm{~kW}$ altında olanlar mikro, 101-1000 $\mathrm{kW}$ arasında olanlar mini, 1001-10000 $\mathrm{kW}$ arasında olanlar küçük, $10000 \mathrm{~kW}$ üzerindeki santraller büyük hidroelektrik santraller olarak adlandirilır $[10,13]$.

Düşülerine göre; alçak (düşü 10 metreden küçük), orta (düşü 10-50 metre arasında) ve yüksek (düşü 50 metreden büyük) düşülü hidroelektrik santraller olarak sınıflandırılır. Depolama durumuna göre ise hidroelektrik santraller genel olarak, rezervuarlı (baraj göllü veya tabi göllü), rezervuarsız (nehir tipi) ve pompaj depolamalı olarak sinıflandırılmaktadırlar. Rezervuarlı (Depolamalı) hidroelektrik santraller, barajlı santraller olarak da isimlendirilmektedir. Burada düzenli ve sürekli elektrik enerjisi üretimi için suyun önü bir baraj ile kapatılarak, barajın gerisinde bir rezervuar oluşturulur. Depolanan su sayesinde üretimin yağış rejimine olan bağımlılığı azaltılır ve yağışsız ve kurak sezonda ihtiyaç duyulan su bu birikmiş hacimden temin edilir. Ayrıca biriken suların meydana getirdiği baraj gölü sayesinde düşü yüksekliği sağlanarak suyun potansiyel enerjisi artırılır. Bu şekilde hidroelektrik santralinden üretilecek elektrik enerjisi miktarı da artırılmış olunur [13].

Nehir tipi hidroelektrik santraller, rezervuarlı hidroelektrik santrallerin aksine debi düzenlemesinin olmadığı, üretimin yağış rejimine bağlı olduğu santral türüdür. Güvenilir elektrik enerjisi üretim miktarı, akarsuyun minimum debisi ile sınırlı olduğundan genelde düşüktür. Bu tip santrallerin kuruluş yerinin seçiminde ideal olan, kurak sezonun hiç yaşanmadığı nehirler üzerinde veya membasın da rezervuarlı hidroelektrik santral bulunan nehirler üzerinde inşa edilmesidir. Böylelikle rezervuarlı hidroelektrik santralin düzenlemiş olduğu debiden istifade edile bilinir. Bu santrallerde bir saptırma savağı ve su alma ağzından kanala verilen su, bir yükleme odasına kadar getirilmektedir. Yükleme odasındaki fazla su için bir taşkın savağı bulunmaktadır. Su bir cebri borudan geçirilerek türbine verilmekte ve burada hidrolik enerjisi mekanik enerjiye çevrilmektedir (Şekil 1). Depolamasız sistemde suyun önü kesilmez, sadece bir kısmı bir kanal içerisine alınır. Bu sistemlerde türbin için gerekli debi, kurak sezonlarda her zaman sağlanamayabilir. Bu sistemlerin en büyük avantajları, yerel olarak çok düşük bir maliyetle inşa edilebilmeleridir. Bu sistemler akarsu yatağına fazla zarar vermezler. Su debisi, yükleme odasında günlük olarak yapılan ayarlarla kontrol edilir $[10,13]$.

Pompaj depolamalı hidroelektrik santraller, alt ve üst olmak üzere iki rezervuardan oluşurlar. $\mathrm{Bu}$ santraller enerji verimliliğinin artırılmasında önemli görev yürütürler. Bu santrallerde; enerji talebinin yüksek olduğu veya elektriğin pahalı olduğu zamanlarda, üst rezervuarda biriktirilmiş olan suyun alt rezervuara düşürülmesiyle elektrik enerjisi üretilir. Enerji talebinin az olduğu zamanlar veya elektriğin ucuz olduğu zamanlarda ise pompa çalıştırılarak su, alt rezervuar seviyesinden üst rezervuar seviyesine yükseltilerek enerji depolamasını sağlarlar. Termik santraller talep değişimlerine hızlı reaksiyon veremedikleri için baz yük santrali olarak kullanılırlar. Hidroelektrik santraller ise kolayca işletilip durdurulabilen ve aynı zamanda kısa sürede tam kapasite yüke çıkabilmeleri nedeni ile pik talebin karşılanmasında kullanılmaktadır. Pik talebin karşılanmasında rezervuarlı hidroelektrik santrallerin yetersiz kalması durumunda pompaj depolamalı hidroelektrik santrallere ihtiyaç duyulmaktadır. Pompaj depolamalı santraller, özellikle rüzgar santrallerinin frekans bozucu etkisi gibi olumsuzluklarını da ortadan kaldıracak şekilde hibrit sistemler olarak çalıştırılabilmekte ve rüzgar santrallerinden elde edilen enerjiyi daha güvenilir hale getirebilmektedir [13, 14].

Hidroelektrik santraller ayrıca baraj gövdesinin tipine göre; ağırlıklı beton gövdeli , beton kemer gövdeli, kaya dolgu gövdeli, toprak dolgu gövdeli olarak sınıflandırılabileceği gibi, santral binasının konumuna göre; yer üstü, yer altı ve yarı gömülü veya batık hidroelektrik santraller olarak da sınıflandırılabilir $[13,15]$. Bu tesisler, kurulacakları yerin topoğrafik yapısına göre çeşitli şekillerde olabilir. Bir hidroelektrik santrali; baraj gövdesi ve gölü, su alma tesisi, suyolları tesisleri, santral binası, santral çıkış suyu kanalı, şalt sahası, dip savak tesisleri, dolu savak tesisleri gibi bölümlerin tamamını veya bir kısmını içerebilir [13]. 


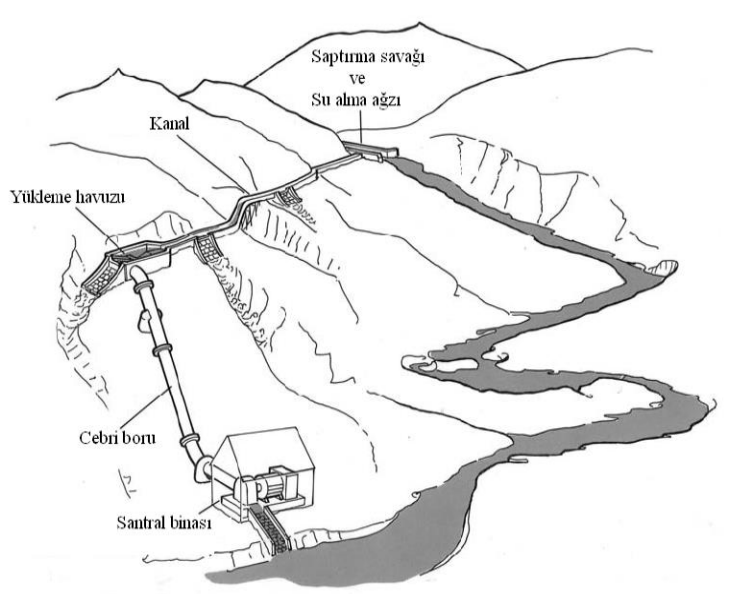

Şekil 1. Nehir tipi hidroelektrik santral [10]

\section{Hidrolik Türbinler}

Türbinler; akışkanda mevcut bulunan serbest haldeki mekanik enerjiyi genellikle üzerinde çarkları bulunan dönen bir mil vasıtasıyla faydalı mekanik enerjiye dönüştürmek amacı ile kullanılan hidrolik makinalardır. Türbinin yapısını akışkan belirlemektedir. Hidrolik türbininin çalışma prensibi şu şekildedir; akışkan türbinin kanatçıklarına çarparak türbin milini çevirmek suretiyle mekanik enerji meydana getirir, daha sonra mekanik enerji jeneratöre iletilir ve burada elektrik üretilir. Hidrolik güç santralleri bu prensibe göre çalışır ve bu santaraller de kullanılan türbinlere hidrolik türbin adı verilir $[10,16]$.

Türbinler, hacimsel ve dinamik olmak üzere iki sınıfa ayrılabilir. Hacimsel türbinler, genellikle güç üretmede değil daha çok hacimsel debi veya akış hacmi ölçümünde kullanılan küçük makinalardır. Dinamik türbinler ise; minyatür yapılardan devasa yapılara kadar farklı yapılara sahip olup, hem akış ölçümünde hem de güç üretiminde kullanılan makinalardır. Su türbinleri suyun etki şekline göre; Etki (aksiyon) ve tepki (reaksiyon) olmak üzere sınıflandırılabilirler. Su türbinleri değişik biçimlerde sınıflandırılmaktadır. $\mathrm{Bu}$ sınıflandırmalar işletme yapısına, dizayn şekillerine, hidrolik düşü yüksekliğine ve akımın yönüne göre yapılmaktadır [16, 17].

Aksiyon türbinlerinde türbin giriş ve çıkışında basınçlar, atmosfer basıncına eşittir. Aksiyon türbinlerine eş basınçlı türbinler denilmektedir. Çünkü bu türbinlerin giriş ve çıkış basınçları birbirine eşittir. Bu türbinler de suya hız kazındırmak için su nozulden geçirilir ve su jeti oluşturulur. Su jeti, türbin çarkı üzerinde çukur çanak şeklinde bulunan kanatlara çarparak türbinin dönmesi sağlanır. $\mathrm{Bu}$ türbinler de Newton'un ikinci yasası ile enerji dönüşümü açıklanır. Bu tip türbinler yüksek düşüler için tercih edilir ve yaygın kullanılan çeşitleri; Pelton, Turgo ve Crossflow (Michell-Banki) türbinleridir. Newton 'un üçüncü yasası ile Francis, Kaplan, Uskur, Propeller, Bulb, Tube, Straflo, Water Wheel gibi çeşitleri olan reaksiyon türbinleri için enerji dönüşümü açıklanır. Reaksiyon tipi su türbinlerinde suyun hem kinetik hem potansiyel enerjisinden faydalanılır. Genellikle, suyun çark çıkışındaki basıncı girişindeki basıncından çok daha küçük olur. Bu sebepten dolayı, suyun kapalı kanallar içinden akma zorunluluğu vardır. Suyun çark çıkışında ivmelenmesinden dolayı meydana gelen tepki kuvvetiyle türbin çarkının dönmesi sağlanır [13].

Hidroelektrik santrallerde kullanılan türbinlerin seçimindeki en belirleyici faktörler hidrolik düşü ve türbinden geçecek olan suyun birim zamandaki hacmi, yani debisidir. Türbin veya jeneratörün hızı türbin tipi seçiminde önemli bir kriterdir. Türbinin kısmi debi koşullarında çalıştırılıp çalıştırılmayacağı ise diğer bir kriterdir. Tüm türbinlerin bir güç-hız ve verim-hız karakteristiği vardır. Türbinin projelendirmesinde imal edilmek istenen esas türbin rotoruna geometrik olarak benzer olan ve $H=1 \mathrm{~m}$ faydalı hidroelektrik düşü ve $Q=1 \mathrm{~m}^{3} / \mathrm{s}^{\prime}$ lik hacimsel debi ve seçilen işletme devrinde $(n)$ çalışan model bir türbin rotorunun $\mathrm{n}_{\mathrm{s}}$ özgül devir sayısı, türbin boyutlarını belirlemektedir. Özgül devir sayısının belirlenmesinden sonra belirli ampirik formüller ile $\mathrm{n}_{\mathrm{s}}$ 'den yararlanılarak türbinin projelendirilmesi yapılmaktadır. Özgül devir sayısı aşağıdaki eşitlikle hesaplanabilir $[10,13]$.

$n_{s}=n Q^{\frac{1}{2}} H^{-\frac{3}{4}}$ 
Türbin ile jeneratör arasındaki hız değişimini en aza indirmek gerekmektedir. Bunun içinde farklı düşüler için farklı türbin tipleri kullanılmalıdır. Bir türbinin hızı, düşü yüksekliğinin karekökü ile doğru orantılı olarak azalmaktadır. Bu sebepten dolayı hızlı türbinler küçük düşülü yerlerde kullanılmaktadır [18, 19]. Tablo 1'de hidrolik düşüye göre türbin tiplerinin kullanım aralığı, Tablo 2'de ise türbin tiplerinin özgül hız değerleri verilmiştir.

Tablo 1. Hidrolik düşüye göre türbin tipleri [10]

\begin{tabular}{cc}
\hline Model & Düşü Aralığ \\
\hline Kaplan ve Propeller & $2<\mathrm{H}<40$ \\
Francis & $10<\mathrm{H}<350$ \\
Pelton & $50<\mathrm{H}<1300$ \\
Banki-Michell & $3<\mathrm{H}<250$ \\
Turgo & $50<\mathrm{H}<250$ \\
\hline
\end{tabular}

Tablo 2. Türbin modellerinin özgül hız değerleri [18]

\begin{tabular}{cc}
\hline Model & Özgül Hız (dev/dak $)$ \\
\hline Pelton & $12-30$ \\
Turgo & $20-70$ \\
Cross-flow & $20-80$ \\
Francis & $80-400$ \\
Kaplan & $340-1000$ \\
\hline
\end{tabular}

\section{Hidrolik Enerji}

Suyun potansiyel enerjisinden elde edilen kinetik enerjiye hidrolik enerji adı verilir. Suyun yüksek seviyeden düşük seviye inmesiyle meydana gelen enerji, hidrolik türbinler kullanılarak mekanik enerjiye ve jeneratör yardımıyla elektrik enerjisine dönüştürülmektedir (Şekil 2). Daha sonra, elektrik enerjisi, elektrik iletim hatları kullanılarak son kullanıcıya nakledilir. Hidrolik potansiyel, yağış rejimine bağlıdır. Bir bölgenin su potansiyeli, yağan yağış miktarı ile belirlenir. Bu sebepten dolayı, iklim şartlarındaki ufak dalgalanmalar, hidroelektrik enerji üretimine etki edecektir [2,12]. Güneş enerjisi ile nehirler, deniz veya göllerden buharlaşan su buharı dağların yamaçlarına yağmur veya kar şeklinde ulaşmakta ve nehirler veya göle geri dönmektedir. Bu sebepten dolayı hidrolik enerji yenilebilir bir enerji kaynağıdır.

Hidrolik türbinlerde enerji elde etmek için suyun mutlaka belirli bir düşü yüksekliğine sahip olmas1 gerekmektedir. Bir hidroelektrik santral tesisinin su düşüsü, üst su yüzeyi ile alt su yüzeyi arasındaki yükseklik farktır. Yukarıda bahsettiğimiz bu hidrolik düşüye brüt hidrolik düşü veya geometrik düşü denir. Bir hidroelektrik santralin su iletim kısımlarında (iletim kanalları, iletim tünelleri, cebri borular, türbin giriş vanaları vs.) su moleküllerinin sürtünmelerinden dolayı kayıplar oluşur. Meydana gelen bu kayıpların toplamı ise $\Sigma \Delta H$ ile gösterilir. Brüt hidrolik düşüden net toplam kayıpların çıkarılması ile net hidrolik düşü bulunur $[12,15]$. Bir hidrolik türbinden üretilebilecek mekanik güç;

$P=\rho g Q H_{0} \eta_{t}$

eşitliği ile ifade edilir [20]. Formülde; $P$ türbin milinden alınan mekanik gücü $(W), \rho$ suyun yoğunluğunu $\left(\mathrm{kg} / \mathrm{m}^{3}\right), g$ yerçekimi ivmesini $\left(\mathrm{m} / \mathrm{s}^{2}\right), Q$ türbine gelen suyun hacimsel debisini $\left(\mathrm{m}^{3} / \mathrm{s}\right), H_{0}$ net hidrolik düşüyü $(m)$ ve $\eta_{t}$ türbinin hidrolik verimini ifade etmektedir. 


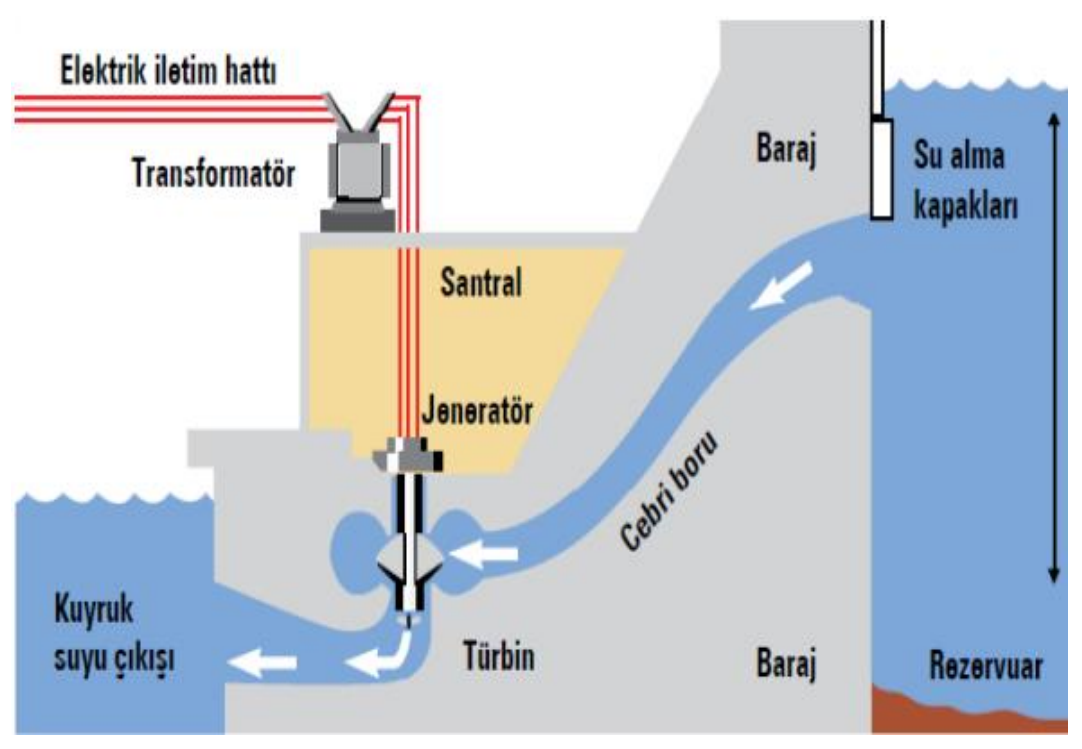

Şekil 2. Hidroelektrik enerji üretimi [21]

\section{Materyal ve Metot}

Bir hidroelektrik santralin rezervuarında depolanan su, cebri buruları doldurur. Rezervuarlı gölde mevcut olan su basıncı ile emme borusundan gelen suyun basınç farkı vardır. Bu basınç farkını gidermek amacı ile salyangoz ile cebri boru arasında bir bypass hattı oluşturulur. Bu bypass hattı üzerinden cebri borudan salyangoza su dolarak basınç fark1 giderilir. Türbinde, potansiyel enerjiye sahip olan su kinetik enerjiye dönüşür. Sonraki aşamada türbin milindeki mekanik enerji bağl1 bulunduğu jeneratör yardımıyla elektrik enerjisine dönüştürülerek hidroelektrik santralinde enerji üretimi gerçekleştirilir.

Örnek uygulamada, Muş İlinde Murat Nehri üzerinde kurulmuş olan Alpaslan-1 Hidroelektrik Santralinin verileri kullanılacaktır. Örnek santralin teknik özellikleri; gövdesi kum çakıl dolgu zonlu kaya, gövde hacmi $3500 \mathrm{dam}^{3}$, Talveg yüksekliği 91 metre (Akarsu tabanından baraj tepesine kadar olan düşey uzaklık), normal su kotunda göl hacmi $2993 \mathrm{hm}^{3}$, normal su kotunda gölalanı $115 \mathrm{~km}^{2}$ 'dir. Hidroelektrik santralde; toplam kurulu gücü $160 \mathrm{MW}$ olan 4 adet ünite bulunmakta, santral $84 \mathrm{~m}$ brüt düşüye sahip olup, santralde özgül hızı 250 dev/dak olan dikey Francis tipi türbin kullanılmaktadır. Santralin her bir ünitenin debisi $55 \mathrm{~m}^{3} / \mathrm{s}$, jeneratörün üretim gücü $45 \mathrm{MVA}$ ve türbin-jeneratör gurubu verimi \%94 alınacaktır [22, 23].

Bir hidroelektrik santralde geleceğe yönelik enerji üretim miktarının tahmini olarak belirlenmesinde; net düşü ve üretim amaçlı kullanılan suyun debi değerinin bilinmesi gerekmektedir. Santralin yıllık üretim planlaması yapılırken aylık gelen su debilerine bağlı olarak göl kotundaki yükselme ve işletme kotlarının alt ve üst kotları dikkate alınarak üretim planlaması yapılır. Tablo 3'de örnek hidroelektrik santralinin üretim planlama tablosu verilmiştir [22]. Santralin üretim planlamasına göre göl işletme eğrisi oluşturulur. Göl işletme eğrisinde, hangi göl kotunda kaç $\mathrm{m}^{3}$ su bulunduğu ifade edilir (Şekil 3). Bu göl hacmine ve ünitede kullanılan suya bağlı olarak yıllık üretim planlaması yapılır. Bu üretim planlamada aylık kaç $\mathrm{m}^{3}$ su geldiği çok önemlidir. Eşitlik 2'de görüldüğü gibi bir hidroelektrik santralde enerji üretim miktarını; net düşü, debi ve verim doğrudan etkiler. Burada verim, debi ve net düşü, direkt olarak göl kotu seviyesine bağlidır. Bu neden ile bu üç etkene bağlı olarak hidroelektrik santralin yükleme grafiğgi oluşturulur. Hesaplamalar bu grafiğge göre yapılır. Tablo 3'de görüldüğü gibi örnek santralin aylık gelen su debisine ve enerji üretimi için harcanan suya göre aylık ve y1llık üretim miktarları görülmektedir. Şekil 4'de örnek santralin göl kotunun aylara göre değişimi verilmiştir. 
Tablo 3. Örnek hidroelektrik santralin 2014 y1lı üretim planlama tablosu

\begin{tabular}{|c|c|c|c|c|c|c|}
\hline \multirow[b]{2}{*}{ Ay } & \multicolumn{2}{|c|}{ Ay Başında } & \multirow{2}{*}{$\begin{array}{c}\text { Giriş } \\
\text { Akım1 } \\
\left(\mathrm{m}^{3} / \mathrm{s}\right) \\
\end{array}$} & \multirow{2}{*}{$\begin{array}{c}\text { Enerji } \\
\text { Üretimi } \\
(\mathrm{MWh})\end{array}$} & \multirow{2}{*}{$\begin{array}{c}\text { Özgül } \\
\mathrm{Su} \\
\left(\mathrm{m}^{3} / \mathrm{kWh}\right) \\
\end{array}$} & \multirow{2}{*}{$\begin{array}{c}\text { Enerjiye } \\
\text { Harcanan } \\
\mathrm{Su}\left(\mathrm{m}^{3}\right) \\
\end{array}$} \\
\hline & $\begin{array}{c}\text { Göl Kotu } \\
(\mathrm{m})\end{array}$ & $\begin{array}{c}\text { Göl Hacmi } \\
\left(\mathrm{m}^{3}\right)\end{array}$ & & & & \\
\hline Ocak & $1.436,59$ & 1.627 .935 .000 & 25,96 & 30.960 & 5,78 & 178.838 .000 \\
\hline Şubat & $1.435,21$ & 1.522 .510 .000 & 30,41 & 25.370 & 5,93 & 150.286 .000 \\
\hline Mart & $1.434,17$ & 1.445 .767 .000 & 118,68 & 31.960 & 4,88 & 182.503 .000 \\
\hline Nisan & $1.435,98$ & 1.580 .817 .000 & 132,56 & 16.750 & 5,34 & 89.452 .000 \\
\hline Mayıs & $1.439,29$ & 1.838 .305 .000 & 82,62 & 5.915 & 4,46 & 26.376 .000 \\
\hline Haziran & $1.441,37$ & 2.027.300.000 & 32,80 & 4.590 & 4,95 & 22.677 .000 \\
\hline Temmuz & $1.442,06$ & 2.089 .650 .000 & 172,00 & 21.134 & 4,96 & 104.817 .000 \\
\hline Ağustos & $1.441,07$ & 2.000 .580 .000 & 2,89 & 14.950 & 5,14 & 76.746 .000 \\
\hline Eylül & $1.440,06$ & 1.912 .305 .000 & 4,03 & 22.960 & 5,37 & 123.322 .000 \\
\hline Ekim & $1.438,59$ & 1.788 .350 .000 & 28,55 & 18.673 & 5,31 & 99.034 .000 \\
\hline Kasım & $1.438,23$ & 1.758 .785 .000 & 27,10 & 17.838 & 5,32 & 94.948 .000 \\
\hline Aralık & $1.437,89$ & 1.731 .150 .000 & 36,35 & 34.800 & 5,41 & 188.200 .000 \\
\hline & \multicolumn{2}{|c|}{ Toplam } & & 245.900 & & 1.337 .199 .000 \\
\hline
\end{tabular}

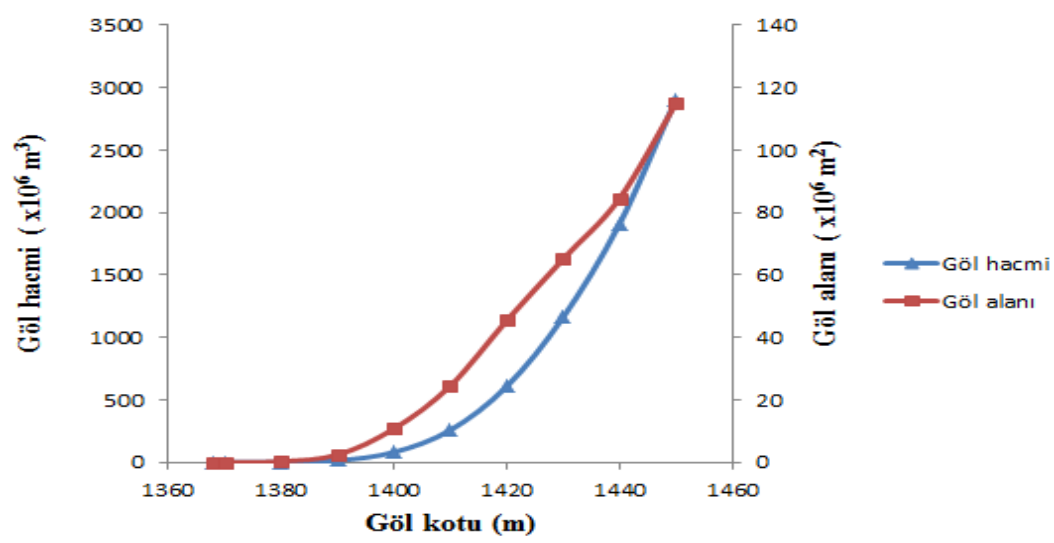

Şekil 3. Örnek hidroelektrik santralin 2014 yllı göl işletme eğrisi

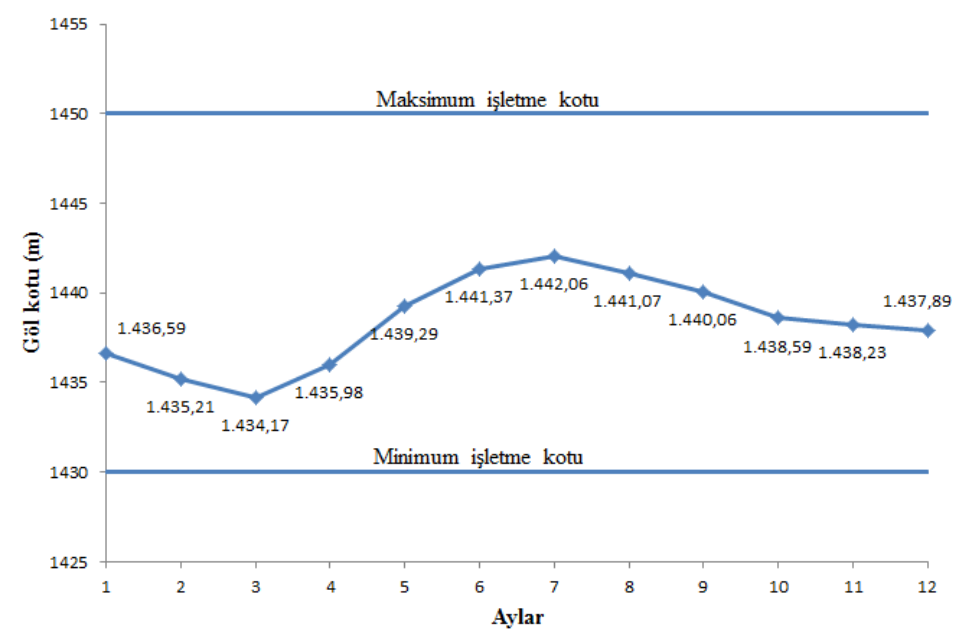

Şekil 4. Örnek hidroelektrik santralin 2014 y1lı göl kotu değişim eğrisi 


\section{Bulgular ve Tartışma}

Tablo 3 incelendiğinde; baraj gölü kotu ve hacminin en büyük değerinin Temmuz ayında, sırasıyla $1.442,06 \mathrm{~m}$ ve $2.089 .650 .000 \mathrm{~m}^{3}$ olarak gerçekleştiği, en küçük değerinin ise Mart ayında, sırasıyla $1.434,17 \mathrm{~m}$ ve $1.445 .767 .000 \mathrm{~m}^{3}$ olduğu görülmüştür. Şekil 4'de göl kotunun Mart ayından sonra artmağa başladığı, Temmuz ayında en yüksek değere ulaştığı ve bu aydan sonra azalmaya başladığı görülmüştür.

Örnek olması amacı ile yukarıda tablo ve grafiklerde değerleri verilen örnek bir hidroelektrik santralinin Mart 2014 tarihinde 4 ünite ile 24 saat çalışması durumunda, aylık üretebileceği enerji miktarı tahmini olarak belirlenecektir. Hidroelektrik Santralin rezervuar gölünde minimum işletme kotu olan 1430 metrede 1.159.689.000 $\mathrm{m}^{3}$, maksimum işletme kotu olan 1450 metre kotunda ise 2.903.446.000 $\mathrm{m}^{3}$ su bulunmaktadır. Bu değerlere göre barajda enerji üretimi amaçlı kullanılabilir su miktarı yaklaşık 1.743.757.000 $\mathrm{m}^{3}$ kadardır. Ayrıca santralin kuyruk suyu çıkış kotu 1367,01 metre, her bir ünitenin debisi $55 \mathrm{~m}^{3} / \mathrm{s}$ olarak alınacaktır. Santralin aybaşı göl kotu; 1434,17 $\mathrm{m}$ ve aybaşı göl hacmi 1.445.767.000 $\mathrm{m}^{3}$ (Göl işletme eğrisinden) değerleri alınır. Santrale aylık gelen suyun miktarı $V_{A G S}$;

$V_{A G S}=Q_{G S D} \times 60($ s/dak) $\times 60($ dak/h) $\times 24(h / g u ̈ n) \times 30($ gün/ay)

eşitliğiyle hesaplanır. Burada $Q_{G S D}$, aylık ortalama gelen suyun debisini ifade etmektedir. Tablo 3'de aylık ortalama gelen suyun debisi 118,68 m³/s alınarak Eşitlik 3 yardımı ile $V_{A G S}$, değeri 307.618 .560 $\mathrm{m}^{3}$ olarak bulunur. Toplam 4 ünite için santralden enerji üretimi esnasında aylık geçen su miktarı $V_{G C ̧ S}$;

$V_{G C S}=Q_{U ̈ D} \times 60($ s/dak) $\times 60($ dak/h) $\times 24(h / g \ddot{u} n) \times 30$ (gün/ay) $\times 4$

eşitliği ile hesaplanır. Burada $Q_{U ̈ D}$ ünite debisini ifade etmektedir. Eşitlik 4 yardımıyla $V_{G C S S}$, değeri 570.240.000 $\mathrm{m}^{3}$ olarak bulunur. Bu durumda santralin ay sonu ay baş1 göl hacim fark1 1.183.145.560 $\mathrm{m}^{3}$ olarak bulunur. Şekil 3'den göl hacmine bağlı olarak ay sonu göl kotu değeri $1432 \mathrm{~m}$ olarak okunur. Toplam enerji üretimi için ay sonu net düşü değeri; ay sonu göl kotu ile santralin kuyruk suyu çıkış kotu $(1367,01 \mathrm{~m})$ arasındaki fark olduğundan bu değer 64,99 $\mathrm{m}$ olarak bulunur. Verilen santral için türbin verimi \%94 alınıp [22], Eşitlik 2 kullanılarak aylık toplam enerji üretim miktarı; 94.928,927 $M W h$ olarak bulunur.

\section{Sonuç ve Öneriler}

Her yıl giderek artan enerji ihtiyacının büyük bir bölümünü ithalat yoluyla gidermeye çalsşan Türkiye'nin, mevcut yerli enerji potansiyelini kullanması, dışa bağımlılığını azaltacaktır. Enerji ihtiyacının son derece önem kazandığı günümüz dünyasında ülkemizin var olan hidroelektrik potansiyelini tamamını kullanması gerekmektedir. Bu amaç ile çevre bilinci içerisinde mevcut hidrolik kaynaklarımızın uygun teknolojik yeni yöntemler ile enerji üretimine kazandırmak, ülkemiz açısından faydalı olacaktır.

Bu çalışmada; hidrolik enerji ve hidroelektrik santraller ile ilgili bilgiler verilerek hidroelektrik santral rezervuar verileri, enerji üretimi amaçlı değerlendirilmiştir. Baraj gölüne giren su debisinin artması ile birlikte göl kotu ve hacminin arttığı, özellikle Temmuz, Nisan, Mart ve Mayıs aylarında bu değerlerin diğer aylara göre daha büyük gerçekleştiği belirlenmiştir. Örnek bir hidroelektrik santralin verileri değerlendirilerek enerji üretimi miktarı tahmin edilmiştir. Bu amaç ile Mart 2014 tarihi için örnek hidroelektrik santralinin enerji üretim miktar1 94.928,927 $M W h$ olarak bulunmuştur. 


\section{Kaynaklar}

1. Tunay M.T., Cebeci M., 2001. Büyük Hidroelektrik Santrallar ile Küçük Hidroelektrik Santralların Karşılaştırılması, Yenilenebilir Enerji Kaynakları Sempozyumu, 18-20 Ocak, İzmir.

2. Gökdemir M., Kömürcü M.İ., Evcimen T.U., 2012. Türkiye'de Hidroelektrik Enerji ve Hes Uygulamalarına Genel Bakış, TMMOB İnşaat Mühendisleri Odası, TMH, 471 (1): 18-26.

3. Akpınar A., 2007. Dünya, Avrupa Birliği ve Türkiye'nin Toplam Elektrik ve Hidrolik Enerji Üretim Projeksiyonu, Karadeniz Teknik Üniversitesi, Fen Bilimleri Enstitüsü, İnşaat Mühendisliği Anabilim Dalı, Yüksek Lisans Tezi, 107s, Trabzon.

4. Uzlu E., Filiz M.H., Kömürcü M.İ., Akpınar A., Yavuz O., 2008. Doğu Karadeniz Havzası'ndaki Küçük Hidroelektrik Santrallerin Durumu, 7. Ulusal Temiz Enerji Sempozyumu UTES'2008, 1719 Aralık, İstanbul.

5. Devlet Su İşleri (DSİ), 2004. Dünden Bugüne DSI 1954-2004, DSİ Etüt Plan Şube Müdürlüğü, Ankara.

6. International Energy Agency (IEA), 2008. Key World Energy Statistics, Paris, Fransa.

7. Eroğlu V., 2006. Tek Sorun Para, Global Enerji, EIE, 19: 26-29.

8. Basmacı E., 2004. Enerji Darboğazı ve Hidroelektrik Santrallarımız, DSİ Vakfı Yayını, Ankara.

9. Ünsal İ., 2003. Turkey's Hydroelectric Potential and Energy Policies, Stradigma E-Journal of Strategy and Analysis, 6: 1-19.

10. Özdemir M.T., Orhan A., Cebeci M., 2011. Çok Küçük Hidrolik Potansiyellerin Enerji Üretim Amacı ile Yerel İmkanlarla Değerlendirilmesi, Elektrik-Elektronik ve Bilgisayar Sempozyumu, Firat Üniversitesi, 5-7 Ekim, Elazı ̆̆.

11. Enerji ve Tabii Kaynaklar Bakanlığı, 2015. Dünya ve Ülkemiz Enerji ve Tabii Kaynaklar Görünümü, Strateji Geliştirme Başkanlığı, Ankara.

12. Başeşme H., 2003. Hidroelektrik Santraller ve Hidroelektrik Santral Tesisleri, II. Bask1, Hidrolik Santraller Daire Başkanlığı Yayınları, Ankara.

13. Yavuzdemir M., 2012. Hidrolik Santrallerin Sınıflandırılması ve Hidrolik Türbin Çeşitleri, Enerji Piyasas1 Bülteni, 24: 59-63.

14. Ünver Ü., Bilgin H., Güven A., 2015. Pompaj Depolamalı Hidroelektrik Sistemler, Mühendis ve Makina, 56: 57-64.

15. Bacanak M.S., 2011. Yeşilırmak Nehrinin Hidroenerji Potansiyelinin Değerlendirilmesinin Araştırılması ve Uygun Türbin Seçimi, Yıldız Teknik Üniversitesi, Fen Bilimleri Enstitüsü, Makine Mühendisliği Anabilim Dalı, Yüksek Lisans Tezi, 125s, İstanbul.

16. Cengel Y.A., Cimbala JM, 2014. Akışkanlar Mekaniği: Temelleri ve Uygulamaları, 3. Baskıdan çeviri, Palme Yayıncılık, Ankara.

17. Özbay E., Gençoğlu M.T., 2009. Hidroelektrik Santrallerin Modellenmesi, 5. Yenilenebilir Enerji Kaynakları Sempozyumu,19-21 Haziran, Diyarbakır. 
18. Özbay E., 2009. Küçük Hidroelektrik Santrallerin Modellenmesi ve Benzetimi, Fırat Üniversitesi, Fen Bilimleri Enstitüsü, Elektrik-Elektronik Mühendisliği Anabilim Dalı, Yüksek Lisans Tezi, 108 s, Elazı $\breve{g}$.

19. Alam M.K., Mirza M.R., Maughan O.E., 1995. Constraints and Opportunities in Planning for the Wise use of Natural Resources in Developing Countries: Example of a Hydropower Project, Environmental Conservation, 22 (4): 352-358.

20. Paish O., 2002. Small Hydro Power: Techology and Current Status, Renewable and Sustainambel Energy Reviewes, 6: 537-556.

21. Environment and Climate Change Canada, 2017. https://www.ec.gc.ca/eauwater/default.asp?lang=en\&n=00EEE0E6-1 (Erişim Tarihi: 15.08.2017).

22. EÜAŞ, 2015. Elektrik Üretim Anonim Şirketi, Alparslan 1 HES İşletme Müdürlüğü, Muş.

23. EÜAŞ, 2017. http://www.euas.gov.tr/Sayfalar/Hidrolik-Santraller.aspx?did=22 (Erişim Tarihi: 28.07.2017) 